\title{
DINAMIKA IKLAN PENGOBATAN ALTERNATIF DI TELEVISI
}

\author{
Dadang Rahmat Hidayat \\ Program Studi Jurnalistik, Fakultas Ilmu Komunikasi, Universitas Padjadjaran
}

\begin{abstract}
ABSTRAK
Tayangan iklan yang mempromosikan produk obat-obatan dan layanan kesehatan makin marak di televisi, baik televisi lokal maupun televisi berjaringan. Ada iklan spot namun sebagian besar lebih panjang dari biasanya (lebih dari 15, 30 atau 60 detik) seolah-olah menjadi program siaran tersendiri yang berbeda dengan tayangan iklan spot. Meskipun memiliki durasi siaran yang panjang, hampir semua iklan obat-obatan dan layanan kesehatan ternyata tidak memberikan informasi medis yang cukup lengkap. Melalui kajian Siaran Iklan Kategori Pengobatan Alternatif yang menggunakan metode deskriptif analitis, diharapkan sedikit banyak analisis yang berorientasi pada penerapan Pedoman Penyelenggaraan Penyiaran (P3) dan Standar Program Siaran (SPS) Komisi Penyiaran Indonesia sebagai implementasi Undang-undang Penyiaran, akan menjadi dasar utama penyusunan kajian ini serta penerapan Etika Periklanan Indonesia/EPI. Penerapan peraturan perundang-undangan lain (Misalnya: Undang-undang Perlindungan Konsumen, Undang-undang Kesehatan, dan lain-lain) diharapkan akan memberikan kontribusi lebih penting di dalam mewujudkan terselenggaranya siaran iklan kategori obat dan kesehatan yang bermanfaat bagi masyarakat sebagai konsumen maupun insan-insan yang menjadi stakeholder siaran iklan kategori ini. Hasil dari analisis ini didapatkan bahwa sebagian besar iklan pengobatan alternatif menggunakan blocking time tersebut melanggar beberapa ketentuan di dalam P3SPS atau Etika Periklanan, antara lain sering menggunakan kata-kata superlatif, menjanjikan penyembuhan dan informasi yang ada tidak lengkap atau sengaja disembunyikan serta merendahkan produk-produk lainnya.
\end{abstract}

Kata-kata kunci: Iklan, pengobatan, etika periklanan, televisi

\section{THE DYNAMICS OF ALTERNATIVE TREATMENT ADVERTISEMENT IN TELEVISION}

\begin{abstract}
Advertisement promoting medicinal products and health services has increased in intensity on television, either local or networked television. There is an ad spot for medicinal products of health services but most of them are longer than usual (the duration of more than 15, 30 or 60 seconds) as if they were their own different broadcasting programs in comparison to commercials spots. Although they have a long duration, almost all advertisement of medicines and health services do not provide a complete medical information. Through the study of Advertisement Broadcast in the Category of Alternative Medicine that uses descriptive analytical method, it is expected that an analysis-oriented of the implementation of Guidelines for Broadcasters (P3) and the Broadcasting Standards Program (SPS). Indonesian Broadcasting Commission as the result of implementation on Broadcasting Law, will be the main basis of this study along with the implementation of Indonesia Advertising Ethics/ EPI. Application of other legislation (for example: the Consumer Protection Act, the Health Act, etc.) are expected to contribute more important in the realization of the broadcasting medicinal advertising category which will be beneficial for the consumers and society as well as people who become stakeholders for this category. The results of this research show that the majority of alternative medicine products have been using ad blocking time, which violated several provisions in the P3SPS or Advertising Ethics. The use the word superlative words, healing promises and incomplete or deliberately hidden information and lowering other products.
\end{abstract}

Keywords: Advertising, medicine, ethics of advertising, television

Korespondensi: Dr. Dadang Rahmat Hidayat, M.Si. Program Studi Jurnalistik, Fakultas Ilmu Komunikasi Universitas Padjadjaran, Jl. Raya Bandung-Sumedang Km.21.Email: dangerha2003@yahoo.co.uk 


\section{PENDAHULUAN}

Media massa pada awalnya hanya berisi informasi berupa berita, atau setidaknya hanya sedikit berisi iklan. Surat kabar misalnya. Pada awalnya hanya mengandalkan penjualan tirasnya, namun kini tidak lagi. Sebagian besar media massa kini berlomba-lomba untuk meningkatkatn porsi iklannya. Hal inilah yang menyebabkan periklanan menjadi bagian strategis dalam perkembangan media massa itu sendiri. Periklanan di Indonesia telah berkembang pesat seiring berkembangnya berbagai media massa di Indonesia. Meski tidak semua iklan menggunakan media massa, tidak bisa dipungkiri bahwa belanja iklan melalui media massa cukup besar. Pengunaan media massa untuk sarana iklan dapat dipahami karena kerakteristik media massa seperti radio dan televisi mempunyai potensi penyebaran yang sangat luas dalam waktu yang tidak terlalu lama.

Segala dinamika penggunaan media untuk periklanan tidak mudah, artinya bukan tidak mungkin menimbulkan hal-hal yang tidak diharapkan oleh siapa pun. Apalagi jika menggunakan media penyiaran, disamping ruang publik yang dirambah oleh iklan, lembaga penyiarannya sendiri menggunakan sarana spektrum gelombang radio atau frekuensi yang memang dimiliki oleh publik. Spektrum frekuensi radio adalah gelombang elektromagnetik yang dipergunakan untuk penyiaran dan merambat di udara serta ruang angkasa tanpa sarana penghantar buatan, merupakan ranah publik dan sumber daya alam terbatas. Oleh karena itu, sangatlah penting jika periklanan yang menggunakan lembaga penyiaran harus diatur sedemikian rupa.

Iklan di lembaga penyiaran khususnya televisi semakin marak dewasa ini dengan munculnya tayangan khusus (blocking time) yang mempromosikan produk obat-obatan dan layanan kesehatan. Tayangan ini dikategorikan sebagai iklan alih-alih sebagai program nonfaktual ataupun news, sebab isi tayangan didominasi oleh promosi produk obat maupun layanan kesehatan. Iklan jenis ini yang memiliki durasi lebih panjang dari biasanya (lebih dari durasi 15, 30 atau 60 detik) seolah-olah menjadi program siaran tersendiri yang berbeda dengan tayangan iklan spot. Meskipun memiliki durasi siaran yang panjang, hampir semua iklan obatobatan dan layanan kesehatan ternyata tidak memberikan informasi medis yang cukup lengkap.

Melalui kajian Siaran Iklan Kategori Pengobatan Alternatif diharapkan sedikit banyak analisis yang berorientasi pada penerapan Pedoman Penyelenggaraan Penyiaran (P3) dan Standar Program Siaran (SPS) sebagai implementasi Undang-undang Penyiaran, menjadi dasar utama penyusunan kajian ini serta penerapan Etika Periklanan Indonesia/ EPI. Penerapan peraturan perundang-undangan lain (Misalnya: Undang-undang Perlindungan Konsumen, Undang-undang Kesehatan, dan lain-lain) diharapkan akan memberikan kontribusi lebih penting dalam mewujudkan terselenggaranya siaran iklan kategori obat dan kesehatan yang bermanfaat bagi masyarakat sebagai konsumen maupun insan-insan yang menjadi stakeholder siaran iklan kategori ini.

Ketentuan yang mengatur periklanan terwadahi dalam Etika Periklanan Indonesia (EPI) dan SPS KPI. Sedangkan penegakannya antara lain diaplikasikan dalam pemantauan penyiaran yang dilakukan KPI. Mekanisme pemantauan penyiaran iklan dikemas dalam sebuah penelitian isi siaran iklan KPI. Ada kemungkinan terjadinya pelanggaran terhadap Pedoman Perilaku Penyiaran dan Standar Program Siaran - Komisi Penyiaran Indonesia (P3 dan SPS - KPI) pada iklan produk berkategori Pengobatan Alternatif, Peraturan Perundang-undangan terkait serta Etika Periklanan Indonesia (EPI). Di samping pelanggaran, dapat diketahui juga mengenai durasi, dominasi penampilan pada iklan antara tokoh laki-laki dan perempuan, tokoh lokal dan asing, toloh masyarakat dan masyarakat biasa, serta sebaran usia pemain iklan.

\section{METODE PENELITIAN}

Metode penelitian yang dilakukan adalah analisis isi dengan data yang bersifat kuantitatif maupun kualitatif. Data yang dikumpulkan berupa durasi tayangan, penggunaan ikon-ikon iklan pengobatan serta konten yang dianalisis berdasarkan peraturan-peraturan yang ada, baik P3SPS KPI maupun Etika Pariwara Indonesia. 


\section{HASIL DAN PEMBAHASAN}

Cukup beragam pengertian tentang periklanan, tapi akan disampaikan beberapa pengertian untuk menjadi rujukan. Dalam kamus komunikasi disebutkan bahwa istilah iklan (advertisement) sendiri adalah pesan komunikasi yang disebarluaskan kepada khalayak untuk memberikan sesuatu atau untuk menawarkan barang atau jasa dengan jalan menyewa media massa, sedangkan periklanan adalah kegiatan menyebarluaskan pesan komunikasi kepada khalayak untuk memberikan sesuatu atau untuk menawarkan barang atau jasa dengan jalan menyewa media massa (Effendy, 1989: 8). Dalam hal ini Onong Uchjana Effendy mensyaratkan menggunakan media massa. Sedangkan Tom Branan mengatakan tidak selalu iklan tersebut menggunakan media massa. Dalam bukunya A Practical Guide to Integrated Marketing Communication, ia menyebutkan iklan sebagai penyampaian sebuah pesan melalui ruangan yang dibayar oleh pemasang iklan (Branan, 1998: 62).

Sedangkan Leder dan Shears (1996) dalam Simatupang (2004) meyebutkan pengertian iklan sebagai berikut:

Advertising means passively promoting product and services. It is conducted using audio and visual media, including printed materialsuchasnewspapersandmagazines, posters, and leaflets. Televisions, whether terrestrial or satellite, radio and even the famous computer "superhighway" are all used by advertisers.

Sampai saat ini belum ada undang-undang khusus bagi periklanan, namun pengaturan tentang periklanan dapat dijumpai dalam berbagai pertaturan perundang-undangan, seperti Undang_undang No. 8 Tahun 1999 tentang Perlindungan Konsumen, Undangundang No. 23 Tahun 1992 tentang Kesehatan dan Undang-undang No. 32 tahun 2002 tentang Penyiaran. Serta Pedoman Perilaku Penyiaran dan Standar Program Siaran (P3SPS) Komisi Penyiaran Indonesia. Di samping aturan yang merupakan hukum negara, terdapat juga pengaturan yang bersifat internal masyarakat perikalan seperti Tata Krama dan Tata cara
Periklanan Indonesia serta Kode etik Periklanan. Keduanya seharusnya saling melengkapi secara komplementer.

Periklanan juga sebenarnya meliputi kegiatan perencanaan, pelaksanaan dan pengawasan pembuatan iklan. Di negara-negara maju periklanan diatur dengan syarat-syarat sah, jujur dan sopan. Iklan diawasi oleh badan pengawas agar iklan tidak melanggar kode etik periklanan yang berlaku. International Chambers of Commerce dengan International Advertising Association pada tahun 1973 (dan terus diperbaiki) mengeluarkan kode etik periklanan internasional.

Penyampaian iklan dapat dilakukan melalui berbagai media yang sengaja ditentukan agar pesan yang disampaikan tepat sasaran dan menghasilkan tujuan seperti yang diinginkan. Media yang digunakan antara lain media publik (non media massa) seperti billboard, spanduk, leaflet, media massa cetak dan media massa elektronik atau penyiaran.

Iklan di lembaga penyiaran merupakan salah satu aspek yang diatur oleh Undangundang No. 32 tahun 2002 tentang Penyiaran. Siaran iklan menurut Undang-Undang Penyiaran adalah siaran informasi yang bersifat komersial dan layanan masyarakat tentang tersedianya jasa, barang, dan gagasan yang dapat dimanfaatkan oleh khalayak dengan atau tanpa imbalan kepada lembaga penyiaran yang bersangkutan.

Undang-Undang Penyiaran menyatakan bahwa jenis siaran iklan ada dua yaitu siaran iklan niaga dan siaran iklan layanan masyarakat. Siaran iklan niaga adalah siaran iklan komersial yang disiarkan melalui penyiaran radio atau televisi dengan tujuan memperkenalkan, memasyarakatkan, dan/atau mempromosikan barang atau jasa kepada khalayak sasaran untuk memengaruhi konsumen agar menggunakan produk yang ditawarkan. Siaran iklan layanan masyarakat adalah siaran iklan nonkomersial yang disiarkan melalui penyiaran radio atau televisi dengan tujuan memperkenalkan, memasyarakatkan, dan/atau mempromosikan gagasan, cita-cita, anjuran, dan/atau pesanpesan lainnya kepada masyarakat untuk mempengaruhi khalayak agar berbuat dan/ atau bertingkah laku sesuai dengan pesan iklan tersebut. 
Berkaitan dengan iklan niaga, UndangUndang No. 32 tahun 2002 tentang Penyiaran mengatur setiap siaran iklan niaga dilarang melakukan hal-hal berikut: (1) promosi yang dihubungkan dengan ajaran suatu agama, ideologi, pribadi dan/atau kelompok, yang menyinggung perasaan dan/atau merendahkan martabat agama lain, ideologi lain, pribadi lain, atau kelompok lain, (2) promosi minuman keras atau sejenisnya dan bahan atau zat adiktif, (3) promosi rokok yang memperagakan wujud rokok, (4) hal-hal yang bertentangan dengan kesusilaan masyarakat dan nilai-nilai agama; dan/atau, (5) eksploitasi anak di bawah umur 18 (delapan belas) tahun. (perlakuan eksploitasi, misalnya tindakan atau perbuatan memperalat, memanfaatkan, atau memeras anak untuk memperoleh keuntungan pribadi, keluarga, atau golongan).

Materi siaran iklan niaga yang disiarkan melalui lembaga penyiaran wajib memenuhi persyaratan yang dikeluarkan oleh KPI. Beberapa hal yang berkaitan persyaratan ini, secara khusus KPI belum mengaturnya, namun ada beberapa hal yang perlu diperhatikan berkaitan dengan Pedoman perilaku Penyiaran dan standar Program Siaran (P3SPS) KPI, yaitu: (a) Lembaga penyiaran tidak boleh menjual jam tayang kepada pihak manapun, kecuali iklan, (b) Lembaga penyiaran dilarang menyajikan program kerjasama produksi atau disponsori oleh perusahaan yang memproduksi produk yang dilarang untuk diiklankan, misalnya minuman keras dan zat adiktif, (c) Lembaga penyiaran dilarang menyajikan program dan promosi program yang mengandung adegan yang dianggap di luar perikemanusiaan atau sadistis, (d) Peserta pemilu dan pilkada dilarang membiayai atau mensponsori program yang ditayangkan lembaga penyiaran, dan (e) Maksimal iklan niaga yang ditayangkan dalam program anak-anak sesuai penggolongan atau klasifikasi program adalah 20\% (duapuluh persen) dari jam tayang program yang bersangkutan. Di samping itu Siaran iklan niaga yang disiarkan pada mata acara siaran untuk anak-anak wajib mengikuti standar siaran untuk anak-anak.

Pemantauan iklan pengobatan alternatif sepanjang Agustus 2010 menghasilkan enam iklan yang keseluruhannya berformat blocking time dengan durasi tayangan 30 menit dan 60 menit. Terdapat tiga stasiun Televisi yang menayangkan iklan pengobatan alternatif ini yakni Metro TV (acara bertajuk Back to Nature, Back to Herbal), Jak TV (acara Medika Natura) dan ANTV (acara Hidup Sehat dengan Ekstrak Herbal bersama Tengku Maulana Sanusi).

Layaknya program lain di televisi, iklan pengobatan alternatif berformat blocking time ini memiliki jadwal penayangan tertentu yakni acara Back to Nature, Back to Herbal di Metro TV setiap Jumat pukul 10.30 -11.00; acara Medika Natura di Jak TV pada Selasa pukul 15.30-16.30 serta acara Hidup Sehat dengan Ekstrak Herbal bersama Tengku Maulana Sanusi di ANTV setiap Sabtu-Minggu pukul 09.00-09.30. Mengenai durasi, figur pengisi program dan pelanggaran terhadap P3SPS dan EPI, secara lengkap hasil penelitiannya sebagai berikut:

Pertama, durasi. Dari enam iklan yang dipantau, mayoritas berdurasi $30^{\prime}(83,3 \%)$ dan hanya satu iklan $(16,7 \%)$ yang berdurasi 60 '. Penggunaan durasi iklan yang lama yaitu 30 ' adalah karena iklan ini menggunakan format live talkshow yang melibatkan adanya interaksi dengan penonton untuk berkonsultasi. Selain itu, durasi lama terkait dengan banyaknya materi yang dirasa perlu disampaikan pada audiens. Kondisi ini menunjukkan bahwa untuk produk sosial, penayangan iklan berdurasi panjang yang disajikan dalam format khusus (blocking time) lebih dibutuhkan mengingat banyaknya pesan yang harus disampaikan pada audiens.

\section{Tabel 1 Durasi Penayangan Iklan}

\begin{tabular}{lll}
\hline Jenis Iklan & Jumlah & Persentase \\
\hline Iklan 30' & 5 & $83,3 \%$ \\
\hline Iklan 60' & 1 & $16,7 \%$ \\
\hline
\end{tabular}

Kedua, figur. Figur iklan dapat terdiri dari berbagai kalangan, namun pada iklan ini menggunakan bintang/selebritis, tokoh masyarakat, dan warga masyarakat. Figur bintang/selebritis ini berfungsi menjadi talkshow host dengan narasumber utama advertiser (pemilik produk yang diiklankan). Bintang/selebritis yang dilibatkan pada iklan kategori Pengobatan Alternatif berprofesi sebagai pembawa acara dan model. 
Tabel 2 Figur Pemain Iklan

\begin{tabular}{|l|c|c|}
\hline \multicolumn{1}{|c|}{ Jenis Figur } & Jumlah & Persentase \\
\hline Bintang / selebritis & 0 & $0 \%$ \\
\hline Pejabat Negara & 0 & $0 \%$ \\
\hline Tokoh Masyarakat & 0 & $0 \%$ \\
\hline Warga Masyarakat & 0 & $0 \%$ \\
\hline $\begin{array}{l}\text { Bintang, Tokoh } \\
\text { Masyarakat \& } \\
\text { Warga Masyarakat }\end{array}$ & 6 & $100 \%$ \\
\hline
\end{tabular}

Ketiga, usia figur. Pilihan pada usia figur dewasa menempati posisi tertinggi pada ke iklan tersebut (100\%). Pilihan produsen iklan menggunakan figurusia dewasa, karena biasanya orang dewasalah yang banyak menderita berbagai macam penyakit, karena pola hidup yang kurang baik atau mengkonsumsi makanan yang kurang sehat.

Tabel 3 Usia Figur Pemain Iklan

\begin{tabular}{|l|c|c|}
\hline \multicolumn{1}{|c|}{ Usia } & Jumlah & Persentase \\
\hline Dewasa & 6 & $100 \%$ \\
\hline Remaja & 0 & $0 \%$ \\
\hline Anak-anak & 0 & $0 \%$ \\
\hline
\end{tabular}

Keempat, jenis kelamin. Jenis kelamin figur adalah pilihan produsen iklan terhadap jenis kelamin pemain iklan produknya. Berdasarkan jenis kelamin, keenam iklan (100\%) dimainkan oleh pria dan wanita secara bersamaan. Pilihan jenis kelamin figur iklan pria dan wanita karena kebutuhan akan kesehatan adalah merupakan kebutuhan pokok yang seimbang baik kepada pria maupun wanita.

Tabel 4 Jenis Kelamin Figur Pemain Iklan

\begin{tabular}{|l|c|c|}
\hline Jenis Kelamin & Jumlah & Persentase \\
\hline Pria & 0 & $0 \%$ \\
\hline Wanita & 0 & $0 \%$ \\
\hline $\begin{array}{l}\text { Pria dan } \\
\text { Wanita }\end{array}$ & 6 & $100 \%$ \\
\hline Waria & 0 & $0 \%$ \\
\hline
\end{tabular}

Kelima, asal figur. Asal figur adalah pembedaan asal negara pemain iklan, yang terbagi sebagai pemain lokal (Indonesia) dan asing (selain Indonesia). Pada tabel 5 ditunjukkan bahwa mayoritas pemain iklan berasal dari Indonesia (lokal) (83,3\%).

Tabel 5 Negara Asal Figur Pemain Iklan

\begin{tabular}{|l|c|c|}
\hline \multicolumn{1}{|c|}{ Asal } & Jumlah & Persentase \\
\hline Asing & 1 & $16,7 \%$ \\
\hline Lokal & 5 & $83,3 \%$ \\
\hline
\end{tabular}

Selanjutnya, penyimpangan terhadap P3SPS - KPI. Dari pemantauan yang dilakukan, terdapat dua penyimpangan iklan dari Ketentuan P3SPS - KPI untuk iklan kategori Pengobatan Alternatif, yakni menampilkan wujud rokok pada tayangan acara Hidup Sehat dengan Ekstrak Herbal bersama Tengku Maulana Sanusi di ANTV versi tumor paru (tayang 28 Agustus 2010) dan menampilkan alat kelamin pada tayangan acara Back to Nature, Back to Herbal di Metro TV (tayang 27 Agustus 2010 pukul 10.30-11.00).

Tabel 6 Penyimpangan Iklan Terhadap P3SPS - KPI

\begin{tabular}{|c|c|c|c|}
\hline No & Pelanggaran Pasal & Jumlah & Persentase \\
\hline 1. & $\begin{array}{l}\text { Merendahkan ajaran agama } \\
\text { tertentu }\end{array}$ & 0 & $0 \%$ \\
\hline 2. & $\begin{array}{l}\text { Merendahkan/melecehkan } \\
\text { pribadi atau masyarakat } \\
\text { tertentu }\end{array}$ & 0 & $0 \%$ \\
\hline 3. & Melecehkan gender & 0 & $0 \%$ \\
\hline 4. & $\begin{array}{l}\text { Mempromosikan minuman } \\
\text { keras atau sejenisnya }\end{array}$ & 0 & $0 \%$ \\
\hline 5. & Menampilkan wujud rokok & 1 & $50 \%$ \\
\hline 6. & $\begin{array}{l}\text { Mengeksploitasi bagian } \\
\text { tubuh }\end{array}$ & 0 & $0 \%$ \\
\hline 7. & Menampilkan alat kelamin & 1 & $50 \%$ \\
\hline 8. & $\begin{array}{l}\text { Gerak/tarian yang } \\
\text { mengandung birahi }\end{array}$ & 0 & $0 \%$ \\
\hline 9. & $\begin{array}{l}\text { Berciuman bibir dan dapat } \\
\text { membangkitkan libido baik } \\
\text { sama atau tidak }\end{array}$ & 0 & $0 \%$ \\
\hline 10. & $\begin{array}{l}\text { Menyentuh/meraba/ } \\
\text { meremas bagian tubuh yang } \\
\text { dapat membangkitkan birahi }\end{array}$ & 0 & $0 \%$ \\
\hline 11. & $\begin{array}{l}\text { Suara-suara yang mengarah } \\
\text { pada hubungan intim }\end{array}$ & 0 & $0 \%$ \\
\hline 12. & $\begin{array}{l}\text { Lirik lagu/jingle yang dapat } \\
\text { membangkitkan hasrat } \\
\text { seksual }\end{array}$ & 0 & $0 \%$ \\
\hline \multirow[t]{2}{*}{13.} & $\begin{array}{l}\text { Mengandung unsur } \\
\text { kekerasan verbal dan } \\
\text { nonverbal }\end{array}$ & 0 & $0 \%$ \\
\hline & JUMLAH & 2 & $100 \%$ \\
\hline
\end{tabular}


Terakhir, pelanggaran terhadap Etika Pariwara Indonesia (EPI). Pelanggaran Etika Pariwara Indonesia iklan kategori Pengobatan Alternatif didominasi oleh: (1) Penggunaan kata-kata superlatif, seperti "paling","nomor satu", "top", atau kata yang berawalan "ter" dan atau yang bermakna sama terdapat pada satu tayangan $(3,8 \%)$ yaitu Back to Nature, Back to Herbal di Metro TV (27 Agustus 2010), (2) Pelanggaran penggunaan " $100 \%$ ", "murni", "asli", untuk menyatakan suatu kandungan, kadar, bobot, tingkat mutu,dan sebagainya, harus dapat dibuktikan dengan pernyataan tertulis dari otoritas terkait atau sumber yang otentik. Pelanggaran ini berasal dari pernyataan host dan advertiser yang menyatakan, "terbuat dari $\mathbf{1 0 0 \%}$ bahan alami dan tidak memberikan efek samping apapun," pada semua tayangan iklan (100\%), (3) Pelanggaran terhadap penggunaan kata gratis dengan kata yang tidak jelas, yang diucapkan oleh Tengku Maulana Sanusi pada acara Hidup Sehat dengan Ekstrak Herbal bersama Tengku Maulana Sanusi di ANTV versi lumpuh $(3,8 \%)$. Pada saat datang kerumah Ibu Suhada, Tengku Maulana menyatakan, "mencoba mengobati dengan ekstrak herbal gratis untuk ibu Suhada"., (4) Ada iklan satu $(3,8 \%)$ iklan yang merendahkan produk lain yaitu Back to Nature, Back to Herbal di Metro TV (27 Agustus 2010). Dalam tayangan tersebut Ada kesan bahwa seringkali pasienpasien yang gagal sembuh melalui pengobatan medis akan memperoleh harapan baru untuk sembuh dengan pengobatan alternatif yang bersangkutan. Jika tidak disertai penjelasan yang benar (Misalnya: hasil bervariasi dan kesembuhan tergantung dari tingkat penyakit, atau adanya saran agar lebih mendahulukan pengobatan medis) akan dapat memberikan pesan bahwa pengobatan alternatif ybs. merupakan hal yang lebih menjamin dibanding pengobatan medis. Jaminan memberikan janji kesembuhan atau memberikan hasil sesuai yang diinginkan dilakukan oleh seluruh iklan, mungkin didasari bahwa sifat dan tujuan obat memang cenderung dapat menyembuhkan, (5) Pelanggaran terhadap memberikan janji kesembuhan pada empat iklan $(15,5 \%)$ yakni pada acara Hidup Sehat dengan Ekstrak Herbal bersama Tengku Maulana Sanusi di ANTV versi Lumpuh dan Parkinson, acara Back to Nature, Back to Herbal di Metro TV (27 Agustus 2010), serta acara Medika Natura yang tayang di Jak TV (21 Agustus 2010), (6) Dalam acara Hidup Sehat dengan Ekstrak Herbal bersama Tengku Maulana Sanusi di ANTV versi lumpuh terdapat pernyataan menjanjikan mutlak seketika dalam kalimat "klinik Secret Herbal komplementer membantu mengatasi berbagai masalah kesehatan, diramu dari bahan alami berkhasiat sehingga aman dikonsumsi dan langsung menyembuhkan pada organ tubuh yang rusak" yang diucapkan oleh Tengku Maulana, pada seluruh iklan (23,1\%), (7) Pelanggaran terhadap penggunan kata yang berlebihan seperti "aman", "tidak berbahaya", "bebas efek samping", "bebas resiko", dan ungkapan lain yang bermakna sama tanpa disertai keterangan yang memadai, yaitu pada kata-kata yang diucapkan oleh host dan advertiser iklan (23,1\%), dan (8) Pelanggaran terhadap menggunakan atribut profesi kesehatan terjadi di semua tayangan $(23,1 \%)$. Semua tayangan menampilkan sosok tokoh ahli pengobatan tradisional. Pada seluruh tayangan Acara Hidup Sehat dengan Ekstrak Herbal bersama Tengku Maulana Sanusi di ANTV diperlihatkan suasana meracik obat di laboratorim bahkan menampilkan Imelda (farmasis) yang memberikan pernyataan tentang kandungan obat. Tayangan Medika Natura menampilkan sosok dokter (dr. Wang) sebagai narasumber utama serta dalam acara Hidup Sehat dengan Ekstrak Herbal bersama Tengku Maulana Sanusi di ANTV versi Parkinson menampilkan DR.dr. Darwis Hartono, Ketua Bidang Hukum dan Organisasi Persatuan Dokter Herbal Medik Indonesia yang memberikan penjelasan keunggulan obat herbal (di dalamnya produk milik advertiser) dari aspek medis. 
Tabel 7 Pelanggaran Iklan terhadap EPI

\begin{tabular}{|c|c|c|c|}
\hline No & Pelanggaran Pasal & Jumlah & Persentase \\
\hline 1. & $\begin{array}{l}\text { Penggunaan kata-kata superlative, seperti } \\
\text { "paling","nomor satu", "top", atau kata yang berawalan } \\
\text { "ter" dan atau yang bermakna sama }\end{array}$ & 1 & $3,8 \%$ \\
\hline 2. & $\begin{array}{l}\text { Penggunaan kata "100\%", "murni”, "asli”, untuk } \\
\text { menyatakan sesuatu kandungan, kadar, bobot, tingkat } \\
\text { mutu, dan sebagainya, harus dapat dibuktikan dengan } \\
\text { pernyataan tertulis dari otoritas terkait atau sumber yang } \\
\text { otentik }\end{array}$ & 6 & $23,1 \%$ \\
\hline 3. & $\begin{array}{l}\text { Kata-kata "presiden", "raja", "ratu", dan sejenisnya } \\
\text { digunakan dalam kaitan atau konotasi yang negatif }\end{array}$ & 0 & $0 \%$ \\
\hline 4. & Pencantuman harga & 0 & $0 \%$ \\
\hline 5. & Penggunaan kata gratis dengan kata yang tidak jelas & 1 & $3,8 \%$ \\
\hline 6. & Penggunaan kata "satu-satunya" & 0 & $0 \%$ \\
\hline 7. & Rasa takut/tahayul & 0 & $0 \%$ \\
\hline 8. & Penonjolan unsur kekerasan & 0 & $0 \%$ \\
\hline 9. & Keselamatan & 0 & $0 \%$ \\
\hline 10. & Eksploitasi anak & 0 & $0 \%$ \\
\hline 11. & Eksploitasi seks & 0 & $0 \%$ \\
\hline 12. & Porno & 0 & $0 \%$ \\
\hline 13. & Merendahkan produk lain & 1 & $3,8 \%$ \\
\hline 14. & Memberikan janji kesembuhan & 4 & $15,5 \%$ \\
\hline 15. & $\begin{array}{l}\text { Menggunakan kata-kata yang berlebihan seperti "aman", } \\
\text { "tidak berbahaya", "bebas efek samping", "bebas } \\
\text { resiko", dan ungkapan lain bermakna sama, tanpa } \\
\text { disertai keterangan yang memadai }\end{array}$ & 6 & $23,1 \%$ \\
\hline 16. & Menjanjikan hasil mutlak seketika & 1 & $3,8 \%$ \\
\hline 17. & $\begin{array}{l}\text { Memberi kesan bahwa penggunaan vitamin, mineral dan } \\
\text { suplemen adalah syarat mutlak bagi semua orang, dan } \\
\text { memberi kesan sebagai obat }\end{array}$ & 0 & $0 \%$ \\
\hline 18. & $\begin{array}{l}\text { Menyatakan bahwa kesehatan, kegairahan dan } \\
\text { kecantikan akan dapat diperoleh hanya dari penggunaan } \\
\text { vitamin, mineral atau suplemen }\end{array}$ & 0 & $0 \%$ \\
\hline \multirow[t]{2}{*}{19.} & Menggunakan atribut profesi kesehatan & 6 & $23,1 \%$ \\
\hline & JUMLAH & 26 & $100 \%$ \\
\hline
\end{tabular}

\section{SIMPULAN}

Penayangan iklam pengobatan alternatif di televisi tampaknya masih harus dicermati dan diperbaiki agar tidak melanggar berbagai ketentuan yang mengatur tentang iklan khususnya mengenai iklan pengobatan atau kesehatan. Pelanggaran yang terjadi dimulai dengan durasi iklan pengobatan alternatif berupa durasi yang berpotensi menambah persentase iklan di sebuah televisi melebihi ketentuan maksimal $20 \%$, apalagi ada beberapa televisi yang menyiarkan iklan pengobatan alternatif lebih dari dua kali dengan durasi 30 sampai 60 menit. Pelanggaran substansi juga tidak sedikit seperti materi pengobatan yang belum tentu bisa dipertanggungjawabkan karena belum tentu mendapat izin dari lembaga yang berwenang 
sampai pada cara penyampaian iklan itu sendiri.

Pelanggaran-pelanggaran yang terjadi dapat disebabkan adanya ketidaktahuan atau pemahaman penyelenggara siaran atas aturan-aturan yang ada, sehingga disarankan perlu adanya sosialisasi kepada lembagalembaga penyiaran, jika sudah mengetahui dan memahami maka tahap selanjutnya adalah melakukan penegakan aturan terhadap lembaga penyiaran yang melanggar.

\section{DAFTAR PUSTAKA}

Branan, T. (1995). A practical guide to integrated marketing communications. London: Kogan Page Limited.

Leiss, W., Kline, T., and Jhally, S. (1986). Social communication in advertising. Ontario Canada: Methuen Publications.

Pedoman Perilaku Penyiaran dan Standar Program Siaran (P3SPS) KPI

Undang-Undang No. 32 tahun 2002 tentang Penyiaran

Simatupang, T. H. (2004). Aspek hukum periklanan. Bandung: Citra Aditya Bakti. 